\title{
A Cognitive Model Of Trust In E-Commerce: Evidence From A Field Study In China
}

Yuan Gao, Ramapo College of New Jersey, USA

Xiaoyu Wu, Ramapo College of New Jersey, USA

\begin{abstract}
Trust formation in the virtual environment is a complex process and is influenced by a plethora of factors. This paper proposes a cognitive model of trust in e-commerce based on consumer research and the trust literature. It argues that perceived informativeness, perceived entertainment, and perceived irritation of online shopping, coupled with trust propensity, contribute to a customer's general trust in e-commerce and intention to use e-commerce. This model is tested in a field study in China via a survey instrument. Path analysis of data collected shows that all proposed relationships in the model are supported in the hypothesized directions. Results demonstrate that online marketers and Web system designers alike should pay keen attention to elements that may influence an Internet shopper's cognitive perceptions in order to nurture consumers' trust in e-commerce and realize the full potentials of doing business online.
\end{abstract}

Keywords: electronic commerce, trust, online shopping, trust in e-commerce, trusting intentions

\section{INTRODUCTION}

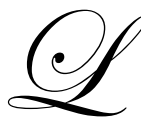
ack of trust online continues to be a main barrier that hinders growth of electronic commerce (ecommerce). In this virtual environment, vendors and customers interact via a Web browser. Customers develop their trust in online firms through elements other than the physical surroundings of a store or face-to-face communications with a salesperson. Previous studies have explored factors influencing consumer trust in e-commerce (EC) or e-business mainly from the perspectives of company reputation and size, third-party assurance, warranties and service quality, and website quality (Kim and Tadisina, 2007). This paper proposes that three cognitive perceptions--informativeness, entertainment, and irritation of the Web-based shopping environment-influence a customer's trust in e-commerce, as well as his or her trusting intentions to use e-commerce in the future.

\section{TRUST ONLINE}

Trust in e-commerce is neither defined by the security mechanisms of the online merchants, nor solely determined by an individual's personal traits (Schneiderman, 2000). Rather, it is a combination of many factors and its formation involves a process of reducing the complexity in decision making in uncertainty (Salam et al., 2003). Consumer trust online can be viewed in four dimensions: trust propensity, general trust of e-commerce, trust in specific companies, and trusting intentions (McKnight et al., 2002). In an exchange relationship, an individual assumes a risk when he or she proffers trust to another person or an institution, i.e., the individual accepts the probability that a hazard may arise in the future as a consequence of proffering trust (Koehn, 2003). In the context of e-commerce, an individual evaluates this risk through familiarity of social and physical cues offered by online businesses, just like inferring someone's values and morality from his behavior and demeanor (Gefen, 2000).

A review conducted by Kim and Tadisina (2007) of 21 research papers on trust published from 1999 to 2006 shows that the existing literature has examined third-party support, company reputation, service quality, website quality, familiarity, and disposition to trust as the main factors that affect a customer's trust in e-commerce. 
However, a consumer's perceptions influence his or her trust beliefs (Jarvenpaa et al., 2000; Lee and Turban, 2001). The cognitive dimensions of perceived informativeness, perceived entertainment, and perceived irritation significantly influence a consumer's attitude toward and perceived value of Web advertising or a Web vendor (Ducoffe, 1996; Liu et al., 2005; Gao and Koufaris, 2006).

Such attitudinal consequences attest directly to a consumer's attitude toward the trustworthiness of online businesses and e-commerce. Thus these cognitive perceptions of online shopping are much related to the general trust in e-commerce as an institution as well as an individual's trusting intentions to use e-commerce. Adapting and extending Koehn (2003), we view trust as a customer's willingness to take a risk in the relationship with ecommerce and define trusting intentions to use e-commerce as a consumer's willingness to rely on or further engage in the exchange relationship for future shopping needs.

\section{COGNITIVE ANTECEDENTS}

Salam et al. (2005) argue that trust does not exist in a vacuum. Rather, it is cultivated by businesses through influencing consumers' beliefs, attitudes and intentions. Therefore, trust develops in an exchange relationship where customers are willing to engage in electronic transactions on the Internet. In the exchange relationship between online shoppers and e-commerce sites, customers who perceive online shopping to be informative, entertaining and organized are more likely to form trust in e-commerce as an institution.

Perceived entertainment or entertainment value, perceived informativeness or amount of information, and organization or approach used in site presentation account for over 50\% of the variance in attitude toward or perceived effectiveness of websites (Chen and Wells, 1999; Eighmey, 1997). After all, customers like informative product presentations in an organized fashion at an entertaining website just like they do in a brick-and-mortar store with a meaningful layout and appealing decor (Koufaris and Hampton-Sosa, 2004).

Information is a major benefit a consumer expects to gain from engaging in an exchange with any media (Bartos and Dunn, 1974). This is true with online shopping as well. Theory of Reasoned Actions (TRA) suggests that a customer's trusting beliefs are in four dimensions: a vendor's benevolence, integrity, competence, and predictability (Fishbein and Ajzen, 1975).

Informativeness of online shopping sites leads to a customer's perception of Web vendors' benevolence, integrity, competence and predictability. For example, complete contact information and return policy add credibility and thus perceived integrity, while detailed FAQs and available feedback mechanisms show the online merchant's concern about its customers' opinions and thus enhance perceived benevolence. Among others, clearly stated security mechanisms for financial transactions and unambiguous estimation of delivery times would most likely enhance a consumer's perception of a Web vendor's competence and predictability. Thus, perceived informativeness of online shopping based on a customer's own experience leads to his or her overall trust in ecommerce and intention to use e-commerce.

H1a: Perceived informativeness of online shopping is positively associated with trust in e-commerce.

H1b: Perceived informativeness of online shopping is positively associated with intention to use e-commerce.

Research on uses and gratifications indicates the entertainment value of a commercial exchange lies in its ability to fulfill the audience's needs for escapism, diversion, aesthetic enjoyment, or emotional release (McQuail, 1983). Likewise, an enjoyable shopping experience enhances an online shopper's attitude toward e-commerce, which leads to trust formation in online shopping.

Entertainment of online shopping speaks to perceived benevolence and in many cases perceived competence of the Web vendor. For example, an e-commerce site that introduces a new product through a short video clip or animated 3D demo not only shows the vendor's goodwill of keeping its visitors entertained but also demonstrates its confidence in its product design and delivery. Thus an entertaining shopping experience enhances the trusting beliefs of a consumer toward the trustworthiness of e-commerce, and hence the following hypotheses: 
H2a: Perceived entertainment of online shopping is positively associated with trust in e-commerce.

H2b: Perceived entertainment of online shopping is positively associated with intention to use e-commerce.

Online vendors sometimes employ tactics such as popup ads and animated banners that annoy visitors. Such techniques often induce irritation (Gao et al., 2004). Visitor feelings of confusion, distraction, and messiness of online shopping sites also contribute to perceived irritation. Irritating shopping experiences could result in a visitor's perception of Web vendors' lack of benevolence, competence, dependability, or even integrity. For example, an ill-structured page layout could cause visitor irritation and frustration because the visitors are unable to navigate the site, to find products, or to buy online, and thus leads to a negative impact on perceived benevolence and perceived competence. On the other hand, mechanisms such as a helpful internal product search engine would minimize frustration, and thus enhance perceived competence and dependability of the online business. These arguments lead to the following hypotheses:

H3a: Perceived irritation of online shopping is negatively associated with trust in e-commerce.

H3b: Perceived irritation of online shopping is negatively associated with intention to use e-commerce.

\section{THE RESEARCH FRAMEWORK}

This research framework proposes a series of hypotheses as discussed in the previous section. Additionally, an individual's trust propensity is a personal trait that influences the formation of trust as well (Kim and Tadisina, 2007). Some individuals exhibit great disposition to trust people or things while others are more reluctant and require more information to form any trusting beliefs (Salam et al., 2003). The influence of trust propensity on an individual's trust in a new institution or phenomenon is especially strong (Mayer et al., 1995). Trust propensity is hypothesized to positively associate with trust in e-commerce.

H4: Trust propensity of the consumer is positively associated with trust in e-commerce.

A customer's trusting beliefs also influence his or her trusting intentions (Liu et al., 2005). A user's trusting beliefs in e-commerce represent an attitude toward the institution of e-commerce. According to TRA, attitude is closely related to behavioral intentions (Ajzen and Fishbein, 1980). Walton et al. (2008), for example, find that higher levels of trust between business partners lead to greater commitment and cooperation. We then anticipate that higher levels of customer trust in e-commerce enhance his/her intention to further engage in e-commerce activities. At the same time, the technology acceptance model (TAM) predicts that attitude toward using technology positively influences intention to use that technology (Davis, 1989; Gefen et al., 2003). Treating shopping online as a form of using a computer-based technology system, we again expect a positive relationship between trust in e-commerce and a user's intention to use e-commerce for future shopping needs. Thus we make the following hypothesis:

H5: Trust in e-commerce is positively associated with intention to use e-commerce.

The research model is outlined in Figure 1. In the diagram, a solid line indicates a positive relation while a dashed line indicates a negative relation.

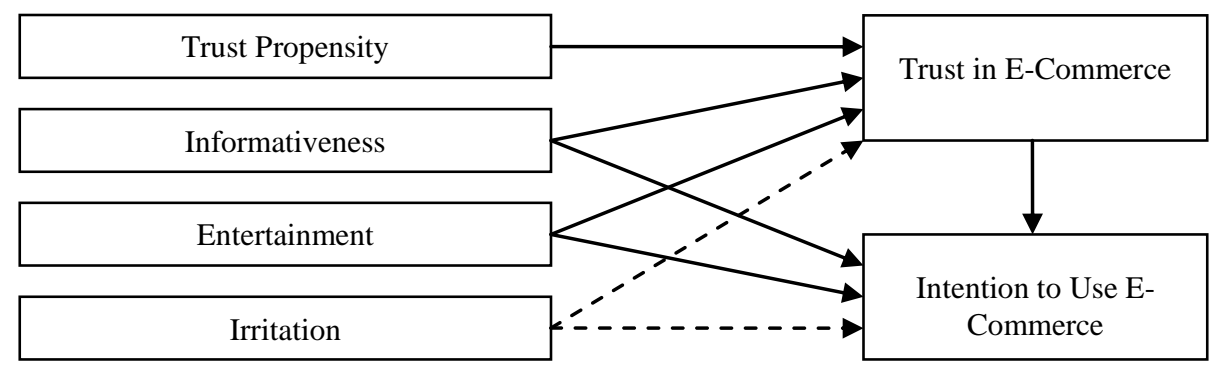

Fig. 1. A Cognitive Model of Trust in E-Commerce 


\section{METHODOLOGY}

Research shows that the Chinese online market has a strong potential for rapid future growth (Yu, 2006). Hofstede (2001) believes that consumers from collectivist societies, where people form strong cultural bonds and common beliefs, tend to view online businesses as less trustworthy than those from individualist cultures, where people tend to be more willing to trust outsiders. Very few empirical studies of online trust have been done in the oriental culture, where personal connections and acquaintances, referred to as guanxi, are essential in business (Greenberg et al., 2008). From that perspective, the Chinese culture is a collectivist one in which trust beyond personal connections and traditional bonds is harder to nurture. Thus it will be more interesting if significant results are found from models testing the trust antecedents in the oriental culture.

A review of trust literature shows that fieldwork using survey methods is a major approach to explore trust online (Olson and Olson, 2000). For this study, scale items measuring the six variables outlined in the model were modified and thus slightly different from those in the existing literature (Ducoffe, 1996; Jarvenpaa et al., 2000; Lee and Turban, 2001; Koufaris and Hampton-Sosa, 2004). Items on the survey instrument were translated into Chinese and used in collecting data for the first time in the Chinese language. Items were mixed and separated on the survey unlike in Appendix A, where items measuring the same variable are stacked together.

The current research model requires a population of Internet users who had experiences shopping online. A college campus in a major city in China was chosen for a field study to test this model. The survey was staged at an outdoor location with heavy foot traffic. Participants voluntarily completed a survey in response to a gift incentive. A screening question turned away all would-be participants who had no or hardly any experience shopping online. Those who filled out the questionnaire were instructed to indicate their agreement or disagreement with each statement on the survey based on their own online shopping experience and their own perception regarding ecommerce. The survey took sample demographics but was anonymous. Appendix A lists the survey items in English.

\section{MODEL TESTING}

Of over a hundred questionnaires distributed 96 were usable for data analysis. About half of the participants were male and half female, ranging from 18 to over 30 years old, with varying levels of education from undergraduate to graduate and varying years of work experience.

Even though scale items were translated from their original form in English into Chinese and thus the internal consistency among items for each scale could be potentially affected, reliability analysis of the scales is favorable. All six variables exhibit high degrees of reliability with the Cronbach's alpha values exceeding the recommended 0.6 (Malhotra, 1993, p. 305).

Table 1. Scale Reliability

\begin{tabular}{|c|c|}
\hline Scale & Cronbach's Alpha \\
\hline Informativeness & 0.607 \\
\hline Entertainment & 0.639 \\
\hline Irritation & 0.648 \\
\hline Trust Propensity & 0.763 \\
\hline Trust in e-Commerce & 0.689 \\
\hline Intention to Use EC & 0.731 \\
\hline
\end{tabular}

Using Structural Equation Modeling (SEM) software AMOS 17.0, a path diagram is constructed, reflecting the hypothesized relationships proposed in the research framework. Path analysis is performed on the model using standardized maximum likelihood estimation. Path analysis with SEM is most appropriate to statistically test a priori hypotheses among a set of observed variables (Gefen et al., 2000). It offers the advantage of testing overall model fit with multiple endogenous variables as well as individual parameters.

The likelihood ratio chi-square test assesses the overall model fit. Chi-square is not significant in this case (Chi-square $=3.061, \mathrm{p}=0.548)$, indicating the model cannot be rejected. Chi-square per degree of freedom 
(CMIN/DF), the relative Chi-square, is 0.765 , satisfying the recommend $<2$ criterion for a good fit. Other indices of model fit including goodness of fit index (GFI), normed fit index (NFI), relative fit index (RFI), incremental fit index (IFI), Tucker-Lewis Index (TLI) and comparative fit index (CFI) all exceed the recommended threshold level of 0.9 (GFI=0.990, NFI=0.982, RFI=0.933, IFI=0.992, TLI=1.023, CFI=1.000). The root mean square error of approximation (RMSEA) is .000, below the recommend < .05 level (McKnight et al., 2002; Gefen et al., 2000). Thus the overall model has a good fit.

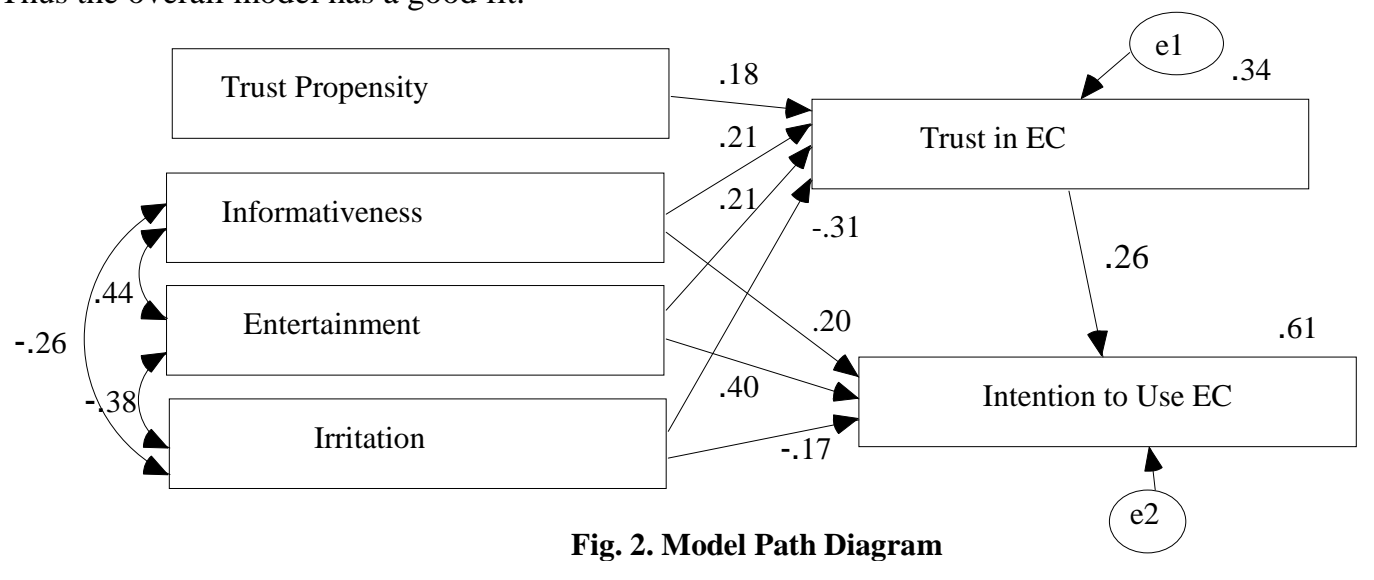

\section{RESULTS}

Correlations among the variables are illustrated in Fig. 2. The model explains $33.7 \%$ of variance in trust in e-commerce, and $60.6 \%$ of variance in intention to use EC. Results indicate the relationships in the proposed model are all statistically significant and in the predicted directions. Four of the eight hypotheses are supported at $\mathrm{p}<0.01$ and the other four at $\mathrm{p}<0.05$.

Informativeness and Trust in EC have a standardized coefficient of $0.212(\mathrm{p}<0.05)$ indicating support for H1a. Entertainment and Trust in EC have a standardized coefficient of $0.21(\mathrm{p}<0.05)$ indicating support for H2a. Irritation and Trust in EC have a standardized coefficient of $-0.308(\mathrm{p}<0.01)$ indicating support for H3a. Trust propensity and Trust in EC have a standardized coefficient of $0.179(\mathrm{p}<0.05)$ indicating support for H4.

Informativeness and Intention to Use EC have a standardized coefficient of 0.201 ( $\mathrm{p}<0.01)$ indicating support for H1b. Entertainment and Intention to Use EC have a standardized coefficient of $0.403(\mathrm{p}<0.01$ ) indicating support for $\mathrm{H} 2 \mathrm{~b}$. Irritation and Intention to Use EC have a standardized coefficient of -0.17 ( $\mathrm{p}<0.05$ ) indicating support for H3b. Finally, Trust in EC and Intention to Use EC have a standardized coefficient of 0.260 ( $p<0.01$ ), indicating support for H5. Table 2 summarizes the results of hypothesis testing.

Table 2 Results of Hypothesis Testing

\begin{tabular}{|l|c|c|}
\hline \multicolumn{1}{|c|}{ Hypotheses } & Std. Coefficients & Results \\
\hline $\begin{array}{l}\text { H1a: Perceived informativeness of online shopping is positively } \\
\text { associated with trust in e-commerce. }\end{array}$ & .212 & $\begin{array}{c}\text { Supported at } \\
\text { p }<.05\end{array}$ \\
\hline $\begin{array}{l}\text { H1b: Perceived informativeness of online shopping is positively } \\
\text { associated with intention to use e-commerce. }\end{array}$ & .201 & $\begin{array}{c}\text { Supported at } \\
\text { p }<.01\end{array}$ \\
\hline $\begin{array}{l}\text { H2a: Perceived entertainment of online shopping is positively associated } \\
\text { with trust in e-commerce. }\end{array}$ & .210 & $\begin{array}{c}\text { Supported at } \\
\text { p }<.05\end{array}$ \\
\hline $\begin{array}{l}\text { H2b: Perceived entertainment of online shopping is positively associated } \\
\text { with intention to use e-commerce. }\end{array}$ & .403 & $\begin{array}{c}\text { Supported at } \\
\text { p }<.01\end{array}$ \\
\hline $\begin{array}{l}\text { H3a: Perceived irritation of online shopping is negatively associated with } \\
\text { trust in e-commerce. }\end{array}$ & -.308 & $\begin{array}{c}\text { Supported at } \\
\text { p }<.01\end{array}$ \\
\hline $\begin{array}{l}\text { H3b: Perceived irritation of online shopping is negatively associated with } \\
\text { intention to use e-commerce. }\end{array}$ & -.170 & $\begin{array}{c}\text { Supported at } \\
\text { p }<.05\end{array}$ \\
\hline $\begin{array}{l}\text { H4: Trust propensity of the consumer is positively associated with trust in } \\
\text { e-commerce. }\end{array}$ & .179 & $\begin{array}{c}\text { Supported at } \\
\text { p }<.05\end{array}$ \\
\hline $\begin{array}{l}\text { H5: Trust in e-commerce is positively associated with intention to use e- } \\
\text { commerce. }\end{array}$ & .260 & $\begin{array}{c}\text { Supported at } \\
\text { p }<.01\end{array}$ \\
\hline
\end{tabular}




\section{DISCUSSION AND FUTURE RESEARCH}

In this study, all of the proposed relations in the research model are supported, indicating consumer perceptions of informativeness, entertainment, and irritation are significant predictors of trust in e-commerce and trusting intentions. This study also validates the impact of trust propensity on trust in e-commerce, which in turn influences an online shopper's intention for further engagement in e-commerce.

This model can also be tested in the context of specific online vendors instead of e-commerce in general. The dependent variable in that case would be trust in a specific company--the only trust construct in McKnight et al. (2002) not included in our current model. That would be a promising avenue for future research.

Sample size and population constitute the main limitations due to our resource constraints. We choose to sample from a college population with a high percentage of Internet users and thus a higher percentage of usable data. However, it reduces our ability to generalize our findings. Nonetheless, illuminating results of this study motivates replication of this study in more general populations and in other cultures to further identify cultural differences that may impact trust differently.

In summary, we show that a customer's cognitive perceptions in the dimensions outlined in this model influence his or her trust in e-commerce and trusting intentions. There still exist barriers to e-commerce acceptance in China in areas such as payment, delivery, and a cultural preference for face-to-face sales or negotiations (Qiu et al., 2003). However, China is making significant progress toward overcoming these barriers with the wider use of bank cards and improving postal services (Yu, 2006). This study demonstrates that firms aspiring to reap the full benefits of e-commerce should pay particular attention to elements that could influence a customer's cognitive perceptions in nurturing trust of online shoppers. Such trust may be the key to the ultimate success of e-commerce.

\section{AUTHOR INFORMATION}

Yuan Gao is an Associate Professor of IS at Ramapo College of New Jersey. He holds an MA in CIS from Brooklyn College, an MBA and a Ph.D. in Business from Baruch College-CUNY. His research interests include human computer interaction, online consumer behavior and current issues in electronic commerce. He is the editor of a scholarly book Web Systems Design and Online Consumer Behavior, published by IGI Global. His research has appeared in DATA BASE for Advances in Information Systems, The Electronic Library, Journal of Electronic Commerce in Organizations, and Journal of Educational Multimedia and Hypermedia.

Xiaoyu Wu is an Assistant Professor of Economics at Ramapo College of New Jersey. She holds a Ph.D. in Economics from the University of California, Riverside. Her research interests include productivity analysis, applied econometrics and environmental economics.

\section{REFERENCES}

1. Ajzen, I. and Fishbein, M. (1980). Understanding Attitudes and Predicting Social Behavior. Prentice-Hall: Englewood Cliffs, NJ.

2. Bartos, R. and Dunn, T.F. (1974). The Consumer View of Advertising. American Association of Advertising Agencies: New York.

3. Chen, Q. and Wells, W.D. (1999). Attitude toward the site, Journal of Advertising Research, 39(5), 27-38.

4. Davis, F.D. (1989). Perceived usefulness, perceived ease of use, and user acceptance of information technology, MIS Quarterly, 13, 319-340.

5. Ducoffe, R.H. (1996). Advertising value and advertising on the Web, Journal of Advertising Research, 36(5), 21-34.

6. Eighmey, J. (1997). Profiling user responses to commercial Web site, Journal of Advertising Research, 37(3), 59-66.

7. Fishbein, M. and Ajzen, I. (1975). Belief, Attitude, Intention, and Behavior: An Introduction to Theory and Research. Addison-Wesley: Reading, MA. 
8. Gao, Y. and Koufaris, M. (2006). Perceptual antecedents of user attitude in electronic commerce, Database for Advances in Information Systems, 37(2-3), 42-50.

9. Gao, Y., Koufaris, M. and Ducoffe, R. (2004). An experimental study of the effects of promotional techniques in Web-based commerce, Journal of Electronic Commerce in Organizations, 2(3), 1-20.

10. Gefen, D. (2000). E-commerce: the role of familiarity and trust, The International Journal of Management Science, 28, 725-737.

11. Gefen, D., Straub, D.W. and Boudreau, M.C. (2000) Structural equation modeling and regression: guidelines for research practice, Communications of the AIS, 4(7), 1-78.

12. Gefen, D., Karahanna, E. and Straub, D.W. (2003). Trust and TAM in online shopping: an integrated model, MIS Quarterly, 27(1), 51-90.

13. Greenberg, R., Wong-On-Wing, B. and Liu, G. (2008). Culture and consumer trust in online businesses, Journal of Global Information Management, 16(3), 26-34.

14. Hofstede, G.H. (2001). Culture's Consequences: Comparing Values, Behaviors, Institutions and Organizations across Nations. Sage Publications: Thousand Oaks, CA.

15. Jarvenpaa, S.L., Tractinsky, N. and Vitale, M. (2000). Consumer trust in an Internet store, Information Technology and Management, 1(1-2), 45-71.

16. Kim, E. and Tadisina, S. (2007). A model of customers' trust in e-businesses: micro-level inter-party trust formation, The Journal of Computer Information Systems, 48(1), 88-104.

17. Koehn, D. (2003). The nature of and conditions for online trust, Journal of Business Ethics, 43(1-2), 3-19.

18. Koufaris, M. and Hampton-Sosa, W. (2004). The development of initial trust in an online company by new customers, Information \& Management, 41(3), 377-397.

19. Lee, M.K.O. and Turban, E. (2001). A trust model for consumer Internet shopping, International Journal of Electronic Commerce, 6(1), 75-91.

20. Liu, C., Marchewka, J., Lu, J. and Yu, C. (2005). Beyond concern: a privacy- trust-behavioral intention model of electronic commerce, Information and Management, 42(2), 289-304.

21. Malhotra, N. K. (1993). Marketing Research: An Applied Orientation. Prentice-Hall: Englewood Cliffs, New Jersey.

22. Mayer, R.C., Davis, J.H. and Schoorman, F.D. (1995). An integrative model of organizational trust, Academy of Management Review, 20(3), 709-734.

23. McKnight, D.H., Choudhury, V. and Kacmar, C. (2002). Developing and validating trust measures for ecommerce: an integrative typology, Information Systems Research, 13(3), 334-359.

24. McQuail, D. (1983). Mass Communication Theory: An Introduction. Sage Publications: London.

25. Olson, J.S. and Olson, G.M. (2000). i2i trust in e-commerce, Communications of the ACM, 43(12), $41-44$.

26. Qiu, B., Chen, S. and Sun, S. (2003). Cultural differences in e-commerce: a comparison between the U.S. and China, Journal of Global Information Management, 11(2), 48-55.

27. Salam, A., Rao, H. and Pegels, C. (2003). Consumer-perceived risk in e-commerce transactions, Communications of the ACM, 46(12), 325-331.

28. Salam, A.F., Iyer, L., Palvia, P. and Singh, R. (2005). Trust in e-commerce, Communications of the ACM, 48(2), 73-77.

29. Schneiderman, B. (2000). Designing trust into online experiences, Communications of the ACM, 43(12), 57-59.

30. Walton, J.R., Salazar, R.J. and Wang, J. (2008). The effects of adaptation, commitment and trust in crosscultural marketing relationships. Journal of Applied Business Research, 24(3), 29-38.

31. Yu, J. (2006). Marketing to Chinese consumers on the Internet, Marketing Intelligence \& Planning, 24(4), 380-392. 


\section{APPENDIX A: Survey Scale Items}

Items are mixed and separated on the survey.

Instruction: Circle the number that best indicates your agreement or disagreement with each statement, from 1 being strongly disagree to 7 being strongly agree.

Perceived Informativeness:

1) E-commerce websites are good sources of product information.

2) E-commerce websites are very informative about products and services they offer.

3) E-commerce websites supply relevant product information.

Perceived Entertainment:

1) Online shopping is enjoyable.

2) Online shopping is entertaining.

3) Online shopping is fun.

Perceived Irritation:

1) I found online shopping sites irritating.

2) Online shopping is frustrating.

3) I found online shopping sites annoying.

Trust Propensity:

1) It is easy for me to trust a person/thing.

2) My tendency to trust a person/thing is high.

3) Trusting someone or something is not difficult.

Trust in e-Commerce:

1) These companies are trustworthy.

2) I trust these companies keep my best interests in mind.

3) These companies want to be known as ones who keep promises and commitments.

4) These companies will not always be honest with me $(R)$.

5) I believe in the information that vendors provide me.

6) These companies are genuinely concerned about me.

Intention to Use e-Commerce:

1) I will visit e-commerce sites frequently in the future.

2) I will search online products or services I may need in the future.

3) I will shop online the next time I need something.

4) It is very unlikely that I will visit any e-commerce site in the future $(R)$.

5) It is impossible for me to buy any product online in the future $(R)$.

6) It is very likely that I will purchase products or services online.

7) I will recommend online shopping to my friends. 